Personalidade Acadêmica Homenageada:

Augustus B. Cochran III (Agnes Scott College)

\title{
INFÂNCIAS ROUBADAS: O PROBLEMA DO ABUSO SEXUAL INFANTIL NA CIDADE DE BELO HORIZONTE-MG
}

\section{STOLEN CHILDREN: THE PROBLEM OF CHILD SEXUAL ABUSE IN THE CITY OF BELO HORIZONTE-MG}

\section{BETHÂNIA PEREIRA GUALBERTO}

Graduanda em Direito, modalidade Integral, pela Escola Superior Dom Helder Câmara. Belo Horizonte-MG. E-mail: bethania.interact@hotmail.com.

CAIO AUGUSTO SOUZA LARA Mestre e Doutor em Direito pela Faculdade de Direito da Universidade Federal de Minas Gerais - UFMG. Professor da Escola Superior Dom Helder Câmara. Pesquisador Associado ao Programa RECAJ-UFMG - Acesso à Justiça e Solução de Conflitos. Secretário de Comunicação do Conselho Nacional de Pesquisa e Pósgraduação em Direito - CONPEDI. Belo Horizonte-MG. E-mail: caiolarabh@yahoo.com.br.

\section{RESUMO}

O tema problema da pesquisa que se pretende desenvolver é o abuso sexual realizado com crianças em Belo Horizonte e os transtornos causados por essa atitude nas vítimas e na sociedade. Um fator importante de ressaltar sobre esse tema e que o levou a ser escolhido é a peculiaridade presente no perfil dos agressores. Eles, na maioria, são pessoas que fazem parte do dia a dia e convivem no mesmo grupo familiar que as crianças. Assim, devido a essa aproximação, fica mais fácil realizar o abuso, uma vez que são vistos como pessoas de confiança e acabam beneficiando 


\section{Personalidade Acadêmica Homenageada:}

Augustus B. Cochran III (Agnes Scott College)

dessa relação afetiva. Após o acontecido, oferecem brinquedos ou mimos para que as vítimas fiquem em silêncio e não comentem com outras pessoas sobre o caso, dificultando o combate do crime e justificando a falta de dados e relatos existentes sobre a temática. Além disso, outro destaque referente ao tema é o de que muitas crianças não entendem que estão sendo exploradas, pois não sabem de fato o que é isso. Como o assunto ainda é considerado um tabu, mesmo em pleno século XXI, não é debatido, na maioria dos casos, nem pelas escolas e nem pelos pais ou responsáveis. Isso acontece, já que muitos indivíduos ainda apresentam seu conhecimento pautado no senso comum e compartilham da ideia de que quanto mais o assunto for discutido, mais ele tenderia a ser realizado e mais cedo aconteceria. $O$ problema objeto da investigação científica proposta é: quais são as consequências para as crianças vítimas de abuso sexual e quais são as políticas públicas existentes e as que podem ser criadas para ajudar no tratamento posterior? A partir das reflexões preliminares sobre o tema, é possível afirmar inicialmente que as crianças que sofrem algum tipo de abuso sexual tendem a apresentar sérios problemas psicológicos que podem comprometê-las para o resto da vida ou até mesmo custá-las a própria vida caso não sejam tratados. $\mathrm{E}$, mesmo o governo apresentando vários órgãos responsáveis por receber denúncias tais como o Conselho Tutelar, o Disque Direitos Humanos (Disque 100) e a Polícia Militar (190) o que realmente ocorre, em grande parte dos casos, é que as políticas públicas existentes não são tão eficazes, apresentam lentidão na busca de uma solução e, como é um assunto delicado, muitos indivíduos possuem medo de realizar denúncias mesmo que em anonimato. O objetivo geral do trabalho é analisar os casos de abuso sexual infantil que acontecem na cidade de Belo Horizonte em suas diversas formas (prostituição, pornografia, tráfico para fins sexuais, turismo como motivação sexual) e como esses acontecimentos influenciam o crescimento e o desenvolvimento das crianças. Ademais, verificar dados sofre a ocorrência desse problema na capital mineira e examinar de maneira mais completa as políticas de auxílio existentes e como essas são executadas na região estudada. A pesquisa que se propõe pertence à vertente metodológica jurídico-sociológica. No tocante ao tipo de investigação, foi escolhido, na classificação de Witker (1985) e Gustin (2010), o tipo jurídico-projetivo. O raciocínio 
Personalidade Acadêmica Homenageada:

Augustus B. Cochran III (Agnes Scott College)

desenvolvido na pesquisa será predominantemente dialético. De acordo com a técnica de análise de conteúdo, afirma-se que se trata de uma pesquisa teórica, o que será possível a partir da análise de conteúdo dos textos doutrinários, normas e demais dados colhidos na pesquisa. Como conclusão parcial do trabalho, tem-se que o abuso sexual infantil que ocorre na cidade de Belo Horizonte não apresenta muitas denúncias e também são deficientes os programas efetivos que ajudem estas crianças a não desenvolverem possíveis traumas e os exploradores a não praticarem o ato novamente.

PALAVRAS-CHAVES: Direito Penal; Abuso Sexual Infantil; Políticas Públicas.

\section{REFERÊNCIAS}

ABUSO e exploração sexual de crianças e adolescentes é tema do programa Expresso 104,5. Portal UFMG Notícias. 18 maio 2018. Disponível em: https://ufmg.br/comunicacao/noticias/abuso-e-exploracao-sexual-de-criancas-eadolescentes-e-tema-do-programa-expresso-104-5. Acesso em 01 maio 2019.

BEZERRA, Carlos. O combate ao abuso e à exploração de crianças e as férias invisíveis. Portal Carta Capital. 18 maio 2018 Disponível em: https://www.cartacapital.com.br/sociedade/o-combate-ao-abuso-e-a-exploracao-decriancas-e-as-feridas-invisiveis/. Acesso em 16 abr. 2019.

BRASIL. Lei 12015, de 2009. Institui a lei dos crimes contra a dignidade sexual. Diário Oficial da União. 2009. Disponível em: http://www.planalto.gov.br/ccivil_03/decretolei/del2848compilado.htm.

CASTRO, Gláucio. MG é o Estado mais vulnerável à exploração sexual de crianças. Portal 0 Tempo. 18 fev. 2017. Disponível em: https://www.otempo.com.br/cidades/mg-\%C3\%A3o-sexual-de-crian-\%C3\%A7as1.1437332. Acesso em 27 abr. 2019.

FERREIRA, Maria Helena Mariante; AZAMBUA, Regina Fay. Violência sexual contra crianças e adolescentes. Porto Alegre: Artmed, 2011.

GUSTIN, Miracy Barbosa de Sousa; DIAS, Maria Tereza Fonseca. (Re)pensando a pesquisa jurídica: teoria e prática. 3ª . ed. Belo Horizonte: Del Rey, 2010. 
Personalidade Acadêmica Homenageada:

Augustus B. Cochran III (Agnes Scott College)

KNOER, Viviane Coêlho de Séllos; MOREIRA, Abel Floriano Kaufman. A exploração do trabalho infantil e sua erradicação como uma questão de Direitos Humanos. Revista Jurídica Unicuritiba. Curitiba, v.1, n.42, p. 451-480,2013. Disponível em : http://revista.unicuritiba.edu.br/index.php/RevJur/article/view/571. Acesso em: 20 maio 2019.

SANTOS, Benedito Rodrigues; GONÇALVEZ, Itamar Batista; VIANA, Vanessa Nascimento. Crianças e adolescentes vítimas ou testemunha de violência sexual. São Paulo: Appris, 2017.

VAMOS combater o abuso sexual de crianças e adolescentes. Portal Mundo Psicológico. $18 \quad$ maio 2019.2 Disponível em: https://br.mundopsicologos.com/artigos/vamos-combater-o-abuso-sexual-decriancas-e-adolescentes. Acesso em 01 maio 2019.

WITKER, Jorge. Como elaborar una tesis en derecho: pautas metodológicas y técnicas para el estudiante o investigador del derecho. Madrid: Civitas, 1985. 